\title{
PENGEMBANGAN ALAT UKUR KEBERSYUKURAN MAHASISWA MUSLIM
}

\author{
Halimatussa'diah, Milya Zakiyah, Muthia Muslimah Almih, Satriani, \\ Yang Dini Azkarisa, dan Dian Sari Utami
}

Fakultas Psikologi dan IImu Sosial Budaya, Universitas Islam Indonesia, Krawitan, Umbulmartani, Kec. Ngemplak, Kab. Sleman, Daerah Istimewa Yogyakarta 55584

Email: satriani.psy95@gmail.com

\begin{abstract}
Abstrak
Skala kebersyukuran mahasiswa muslim dikembangkan berdasarkan aspek yang dibagi menjadi butiran item yang diuji kepada 132 orang mahasiswa muslim (laki-laki berjumlah 35 dan perempuan berjumlah 97) dengan rentang usia 18 - 30 tahun dengan menguji validitas dan reliabilitas skala. Analisis faktor yang digunakan yaitu analisis faktor eksploratori (EFA), yang diekstraksi dengan melihat besaran nilai Barlett Test of Sphericity $=455.929$ dengan taraf signifikansi 0,000 yang berarti ada korelasi yang signifikan di antara variabel. Hasil perhitungan KMO sebesar 0,830 menunjukkan bahwa kecukupan sampel termasuk kategori atas. Uji reliabilitas kesuluran aitem berdasarkan nilai cronbach alpha yang didapatkan adalah 0.851 dengan nilai Corrected item-total correlation bergerak dari $0.413-0.608$, dimana alat ukur kebersyukuran ini reliabel.
\end{abstract}

Kata kunci: faktor analisis eksploratory, kebersyukuran.

\section{DEVELOPMENT OF GRATITUDE SCALE FOR MUSLIM STUDENTS}

\begin{abstract}
The Moeslem gratitude scale for college students was developed based on aspects devided into items that were tested on 132 Moeslem College students (35 men and 97 women) with an age range beetwen 18 - 30 years old by testing the validity and reliability of the scale. Factor analysis used is exploratory factor analysis (EFA), which was extracted by looking at the value of the Barlett Test of Sphericity $=455.929$ with a significance level of 0.000 which means there is a significant correlation between variables. The KMO calculation result of 0.830 shows that the adequacy of the sample is in the upper category. The reliability if the item based on Chronbach Alpha value obtained is 0.851 with the corrected item-total correlation moving value from $0.413-0.608$, where the gratitude measurement tool is reliable.
\end{abstract}

Keyword: exploratory factor analysis, gratitude.

\section{Pendahuluan}

Kajian ilmu psikologi saat ini khususnya kajian psikologi positif saat ini mulai menjadi perhatian para ahli psikologi dalam mengungkapkan masalah-masalah sosial yang terjadi di tengah masyarakat dan membantu manusia mencapai kebahagiaan melalui emosi-emosi positif. Kajian psikologi positif ini berguna untuk dikaji agar manusia dapat melangsungkan hidupnya dengan lebih baik. Salah satu hal yang dapat dikaji dalam psikologi posisit adalah syukur. 
Halimatussa'diah, Milya Zakiyah, Muthia Muslimah Almih, Satriani, Yang Dini Azkarisa, dan Dian Sari Utami

Kebersyukuran atau gratitude berasal dari bahasa latin 'gratita' yang berarti kebaikan, murah hati, bantuan, keindahan dalam tindakan kebaikan (Pruyser, 1976). Kebersyukuran juga diungkapkan oleh beberapa teori konvensionalyang dituangkan dalam perspektif psikologi positif oleh Peterson \& Seligman (2004) bahwa kebersyukuran merupakan rasa terimakasih dan kesediaan dengan suka cita menerima pemberian dari orang lain atau kemampuan menikmati keindahan alam dan memperoleh kedamaian dari hal itu. Hal senada juga diungkapkan oleh Emmons \& McCullogh (2004) mendefinisikan kebersyukuran sebagai salah satu emosi dasar yang diperlukan untuk stabilitas individu, ungkapan dan tindakan kebersyukuran kepada Tuhan maupun sesama manusia merupakan suatu kebajikan yang telah diakui secara universal. Kebersyukuran secara tradisional muncul dalam konteks religi. Kebersyukuran dengan kata dasar syukur dalam Islam berasal dari bahasa Arab 'syakara' yang berarti pujian, atas kebaikan, terpenuhinya sesuatu, dan memberikan sebagian nikmat yang telah diterima kepada orang lain yang membutuhkan. Menurut istilah, syukur adalah memberikan pujian kepada yang memberi kenikmatan dengan sesuatu yang telah diberikan kepada kita berupa perbuatan makruf dalam pengertian tunduk dan berserah diri kepada-Nya (Al- Banjari, 2014). Dari berbagai pengertian diatas dapat diambil kesimpulan bahwa syukur adalah suatu ungkapan terimakasih dalam beberapa hal yang dihadapi oleh umat manusia yang dengan rasa syukur itu berfokus pada ungkapan terimakasih mendalam pada Tuhan, orang sekitar bahkan dirinya sendiri.

Dalam pengaplikasiannya menurut Rauf \& Alif (2008) menyatakan bahwa syukur merupakan segala pujian atas kebaikan yang diterima, dirasakan, dinikmati manusia dengan melibatkan keridhoan beserta kepuasan atas nikmat walau hanya sedikit. Syukur seseorang saat mengakui kekurangan dalam berterimakasih terhadap zat yang telah memberi nikmat tidak mencela sesuatu yang tidak ia miliki dan ia tidak mementingkan hawa nafsu sehingga rasa syukur tersebut tetap terjaga. Orang yang bersyukur akan menciptakan kelekatan dalam diri sehingga membentuk kepribadian, dimana pribadi yang penuh syukur (grateful personality) tidak larut dalam lamunan akan berbagai keinginan yang belum atau tak akan pernah diperoleh, tetapi senantiasa dipenuhi sukacita akan segala hal yang sudah diberikan orang lain kepada mereka. Sehingga dengan kebersykuran tersebut manusia akan senantiasa membangun potensinya dan tidak terpengaruh dengan sesuatu hal yang tidak ia miliki. Hal ini juga sepadan dengan sifat syukur adalah seeperti tawadhu', menjaga kebaikan-kebaikan, melawan nafsu syahwat, bersungguh-sungguh mengerjakan ketaatan dan senantiasa merasakan pengawasan dari penguasa langit dan bumi (Al- Banjari, 2014). Sehingga bisa dikatakan bahwa hakikat dari kebersyukuran merupakan suatu kondisi dimana nikmat yang diberi Allah digunakan untuk beribadah dan tidak digunakan untuk bermaksiat. Hakikat syukur adalah terlihatnya pengaruh nikmat Allah pada lisan hamba-Nya dalam bentuk sanjungan, pada hati dalam bentuk pengakuan, dan pada anggota badan dalam bentuk ketaatan dalam beribadah. Dalam penjagaa diri dalam hal maksiat ini lebih kepada saat seseorang mampu merawat dirinya dan menjaga potensi yang ia miliki sehingga keimanan dan dirinya sendiri juga akan terjaga dengan baik. Dengan pengembangan potensi tersebut diharapkan mampu diri seseorang itu dapat meningkatkan kualitas diri

Dalam peningkatan kualitas diri seseorang ia akan merasakan syukur dalam dirinya ia akan secara sadar merasakan ketenangan dan biasanya ia akan mengucapkan terimakasih atas apa yang ia dapatkan 
atau ucapakan. Sebagian rasa syukur tersebut juga berdampak pada emosi yang dirasakan seseorang di mana emosi yang berpengaruh pada hal positif yang dirasakan dan mengurangi emosi negatif. Rasa syukur ini lebih kepada timbulnya emosi postif yang dirasakan. Hal tersebut juga pernah diteliti oleh Sheldon dan Sonja (2006) yang mana pada penelitan ini menunjukkan bahwa kebersyukuran dapat mengurangi emosi negatif pada diri seseorang. Senada dengan penelitian diatas penelitian kebersyukuran lain juga mengungkapkan juga bahwa bersyukur menciptakan pengaruh positif dan mengurangi pengaruh negatif, bertanggung jawab pada intervensi positif dimana ada peningkatan kualitas hidup, kualitas tidur seseorang dan kepuasan hidup bagi yang memiliki pasangan secara signifikan (Anggraini, Andayani dan Karyanto, 2013; Breen, Kashdan, Lenser dan Fincham, 2010; Dewanto dan Retnowati, 2015; Emmons, McCullough dan Tsang, 2002; Emmons dan McCullough, 2003; Putri, Sukarti dan Rachmawati, 2016; Rahmawati, Tresnaningrum dan Sari, 2016). Dengan emosi positif yang akan muncul tesebut secara tidak sadar pengaruh syukur akan meningkatan kulitad diri seseorang sehingga psikologis seseorang akan menjadi lebih dan manusia akan lebih tentram dalam menjalani hidup.

Dari beberapa penelitian diatas kebersyukuran menjadi salah satu faktor yang sangat berperan dalam kepuasan dan kesejahteraan dan kebahagiaan diri seseorang, dimana dapat menciptakan suasana hati tenang dan bahagia sehingga tidak merasa kurang terhadap apa yang diberikan Tuhan. Selain itu pada penelitian yang lain oleh Romdhon (2011) yang mana dalam penelitian ini menunjukkan bahwa orang yang bersyukur akan mudah mencapai kebahagiaan dan kehidupan yang penuh ketentraman serta lebih mudah dalam menghadapi berbagai permasalahan hidup atau keadaan yang menekan (stressfull). Berdasarkan penelitian ini juga selaras dengan hakikat syukur yang ada dalam kajian islam yang selama ini sangat dikenal terutama bagi umat muslim itu sendiri baik itu dalam pemahaman maupun dalam prakter sehari-hari seperti pengucapan "Alhamdulillah" sebagai simbol dari rasa kebersyukuran itu sendiri.

Syukur sesungguhnya tidak hanya cukup pada pengucapan tersebut, karena syukur berkaitan dengan lisan, hati dan anggota badan (Al-Ghazali, 2005). Hal senada juga dipaparkan oleh Ibnu Manzhur, yang mana syukur artinya adalah membalas nikmat dengan ucapan, perbuatan, dan disertai dengan niat (Al Fauzan, 2013). Pemahaman mengenai syukur, khususnya pada masyarakat Indonesia yang beragama Islam tentunya diperoleh melalui ajaran-ajaran dalam Islam, yang juga dipengaruhi oleh budaya yang ada dalam Indonesia. Rasa syukur merupakan energy positif yang dimiliki individu sehingga dapat berpengaruh pada kebahagiaan dan ketenangan jiwa. Rasa syukur berkaitan dengan bagaimana pandangan individu terhadap kehidupannya dan bagaimana cara menyikapi hal-hal yang terjadi di lingkungan sekitarnya. Sehingga kebersyukuran atau gratitude bukan lagi sekedar emosi sesaat, tapi lebih kepada tingkah laku yang menetap (trait), menjadi bagian dari jati diri (part of character), serta merupakan moral yang menggerakan individu untuk memberikan kontribusi khas dalam dirinya. Berdasarkan pendapat di atas, maka dapat disimpulkan bahwa kebersyukuran adalah suatu tindakan yang mengungkapkan rasa terimakasih atas pujian dan kebaikan yang diperoleh dari orang lain maupun dari Allah. Rasa terimakasih tersebut ditampilkan dalam bentuk perkataan dan tingkah laku. Rasa syukur yang dimiliki individu akan mengarahkan kehidupannya menjadi semakin lebih baik dan memberikan manfaat pada diri sendiri dan orang lain. 
Berdasarkan penjelasan diatas kami selaku peneliti tertarik untuk mebuat konstruksi alat ukur kebersyukuran untuk melihat tingkat kebersyukuran pada individu khusunya pada umat yang beragama Islam.

\subsection{Tujuan penelitian}

Tujuan penelitian untuk mengembangkan alat ukur psikologi kebersyukuran pada mahasiswa muslim.

\subsection{Dimensi Kebersyukuran}

a. Internal

Bentuk syukur ini adalah proses rela dan menerima nikmat dengan ilmu dan hati.

b. Eksternal

Bentuk syukur ini dilakukan kepada allah dan sesama dalam bentuk ekspresi dan respon perilaku atas nikmat Allah.

\section{Metode penelitian}

Berdasarkan permasalahan di atas maka penelitian ini menggunakan metode penelitian kuantitatif. Penelitian kuantitatif adalah suatu penelitian yang pada dasarnya menggunakan pendekatan deduktifinduktif. Pendekatan ini berangkat dari suatu kerangka teori, gagasan para ahli, maupun pemahaman peneliti berdasarkan pengalamannya, kemudian dikembangkan menjadi permasalahan-permasalahan beserta pemecahan-pemecahannya yang diajukan untuk memperoleh pembenaran (verifikasi) atau penolakan dalam bentuk dukungan data empiris dilapangan. Penelitian ini dilakukan di Daerah Istimewa Yogyakarta. Partisipan dalam penelitian ini berjumlah 132 orang (laki-laki berjumlah 35 dan perempuan berjumlah 97), dengan kriteria: beragama Islam, mahasiswa yang sedang menempuh pendidikan di Yogyakarta, berusia 18 sampai 30 tahun, variabel dalam penelitian adalah kebersyukuran.

Secara konseptual kebersyukuran adalah suatu tindakan yang mengungkapkan rasa terimakasih atas pujian dan kebaikan yang diperoleh dari orang lain maupun dari Allah. Rasa terimakasih tersebut ditampilkan dalam bentuk perkataan dan tingkah laku. Rasa syukur yang dimiliki individu akan mengarahkan kehidupannya menjadi semakin lebih baik dan memberikan manfaat pada diri sendiri dan orang lain.

Secara operasional, kebersyukuran adalah suatu tindakan yang mengungkapkan rasa terimakasih atas pujian dan kebaikan yang diperoleh dari orang lain maupun dari Allah dalam bentuk perkataan dan tingkah laku. Kebersyukuran diukur dengan menggunakan skala kebersyukuran yang disusun oleh peneliti berdasarkan pendapat para ulama, dimana syukur terbagi 2 dimensi yaitu internal dan eksternal.

Semakin tinggi skor skala, menunjukkan semakin tinggi kebersyukuran seseorang. Begitu juga sebaliknya. Di bawah ini merupakan blueprint dari skala kebersyukuran. 
Tabel 1. Blueprint Kebersyukuran

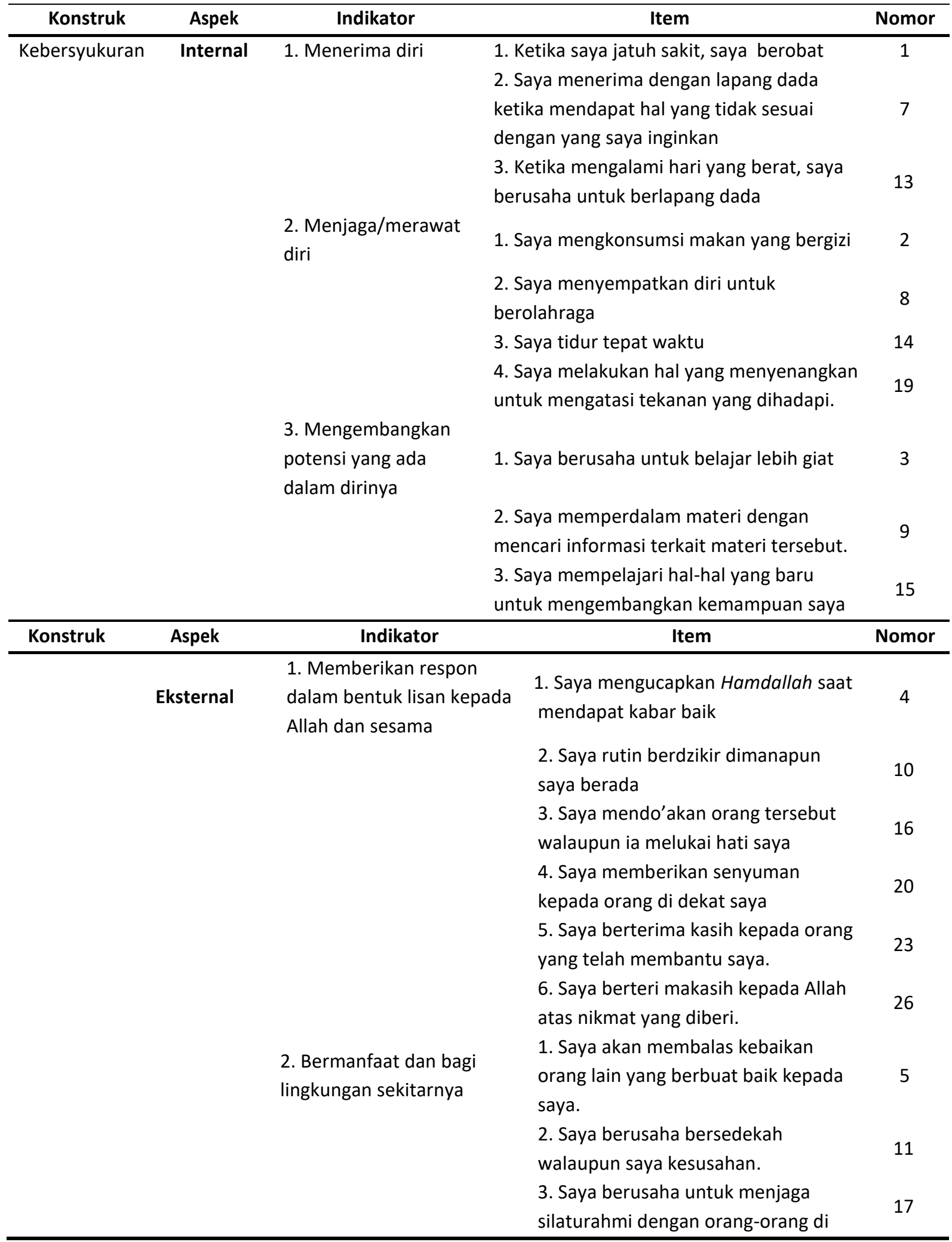


Halimatussa'diah, Milya Zakiyah, Muthia Muslimah Almih, Satriani, Yang Dini Azkarisa, dan Dian Sari Utami

sekitar saya.

4. Ketika seseorang meminta

bantuan, saya tetap membantunya 21

walaupun sedang kerepotan

5. Saya memberikan uang kepada

orang yang meminta-minta,

walaupun jumlah uang yang saya

24

miliki sedikit.

3. Taat pada perintah Allah

1. Meskipun saya sibuk, saya tetap

mengerjakan sholat 5 waktu

2. Saya mendengarkan dan

menerima nasehat dari orang tua

maupun orang lain.

3. Saya menyisihkan uang untuk

bersedekah

4. Saya menyempatkan diri untuk

membaca Al-Qur'an setiap hari

5. Saya rutin puasa Sunnah Senin

Kamis

\section{Analisis data}

Analisis data adalah proses mengatur urutan data serta mengorganisasikan ke dalam suatu pola, kategori dan satuan uraian dasar. Analisis data adalah rangkaian kegiatan penelaah, pengelompokan, sistematisasi, penafsiran dan verifikasi data agar sebuah fenomena memiliki nilai sosial, akademis dan ilmiah. Adapun analisis data yang digunakan pada penelitian ini adalah analisis faktor.

\section{Hasil}

Validitas isi, sebelum dilakukan penyebaran skala kebersyukuruan, terlebih dahulu peneliti melakukan validitas isi dengan menggunakan expert judgement oleh salah satu ahli psikologi positif. Setelah dilakukan validitas isi dari expert dari 26 aitem yang dibuat peneliti 4 aitem dinyatakan gugur. Dilakukan kembali revisi aitem-aitem yang gugur tersebut sehingga skala tetap memiliki 26 aitem.

Validitas konstruk dengan menggunakan analisis faktor. Analisis faktor yang digunakan dalam penelitian ini adalah exploratory factor analisis. Hasil analisis menunjukkan salah satu aitem memiliki nillai MSA <0.500 yaitu aitem 1 dengan nilai MSA 0.446, kemudian didapatkan nilai KMO sebesar 0.812 (>0.7) dengan nilai signifikansi $0.000(<0.05)$. dikarenakan masih ada aitem yang memiliki nilai $\mathrm{MSA}<0,5$ maka dilakukan analisis kembali dengan membuat aitem 1 . Hasil analisis kemudian menunjukkan tidak ada aitem yang memiliki nilai $\mathrm{MSA},<0.05$ dan nilai KMO yang didapatkan adalah 0.823 serta nilai signifikansinya 0.000 (<0.05). Menurut Leech dkk (2005), bila nilai KMO lebih besar dari 0.700 dengan nilai signifikansi $<0,05$ menunjukkan butir aitem berkorelasi tinggi sehingga dapat dilakukan analisis faktor. Hasil analisis faktor dengan putaran rotasi orthogonal (varimax) skala kebersyukuran membentuk 7 faktor. Hasil analisis ini dapat dilihat pada tabel 2. 
Tabel 2. Nilai Loading 0.30

Rotated Component Matrix ${ }^{a}$

\begin{tabular}{llllllll}
\hline & \multicolumn{3}{c}{ Component } \\
\hline & 1 & 2 & 3 & 4 & 5 & 6 & 7
\end{tabular}

5. Saya akan membalas kebaikan orang lain yang berbuat baik kepada saya.

.758

17. Saya berusaha untuk menjaga silaturahmi dengan orangorang di sekitar saya.

21. Ketika seseorang meminta bantuan, saya tetap membantunya walaupun saya juga kesulitan.

12. Saya mendengarkan dan menerima nasehat dari orang tua maupun orang lain

13. Ketika mengalami hari yang berat saya berusaha untuk berlapang dada

16. Saya mendo'akan orang tersebut walaupun ia melukai hati saya

4. Saya mengucapkan Hamdallah saat mendapat kabar baik

11. Saya berusaha bersedekah walaupun saya kesusahan.

6. Meskipun saya sibuk, saya tetap mengerjakan sholat 5 waktu

22. Saya menyempatkan diri untuk membaca Al-Qur'an setiap hari

10. Saya rutin berdzikir di manapun saya berada

25. Saya rutin puasa Sunnah Senin Kamis

9. Saya memperdalam materi dengan mencari informasi terkait materi tersebut

3. Saya berusaha untuk belajar lebih giat

15. Saya mempelajari hal-hal yang baru untuk mengembangkan kemampuan saya

19. Saya melakukan hal yang menyenangkan untuk mengatasi tekanan yang dihadapi.

20. Saya memberikan senyuman kepada orang didekat saya

8. Saya menyempatkan diri untuk berolahraga

2. Saya mengkonsumsi makan yang bergizi

14. Saya tidur tepat waktu

18. Saya menyisihkan uang untuk bersedekah

26. Saya berterima kasih kepada Allah atas nikmat yang diberikan-Nya

23. Saya berterima kasih kepada orang yang telah membantu saya.

24. Saya memberikan uang kepada orang yang meminta-minta, walaupun jumlah uang yang saya miliki sedikit.

7. Saya menerima dengan lapang dada ketika mendapat hal yang tidak sesuai dengan yang saya inginkan.
.507

.425

.724

.692

.656

.346

.334

.592

.504

.494

.387

.829

.807

.629

.370

.512

.306

.736

.688

$.326 \quad .634$

.380

.605

.568

.348

.735

.661

$.308 \quad .599$

.581

.828

$.337 \quad 636 \quad .310$

.685

$.346 \quad .345$

.399

.407

Extraction Method: Principal Component Analysis. 
Rotation Method: Varimax with Kaiser Normalization.

a. Rotation converged in 14 iterations.

Costello dan Osborne (2005) mengatakan bahwa struktur faktor telah murni atau fit jika faktor loading lebih besar dari 0,3, tidak ada crossloading (satu aitem memiliki faktor loading yang tinggi pada dua atau lebih faktor yang terbentuk), dan dalam satu faktor minimal ada 3 aitem (faktor yang kurang dari 3 aitem dianggap tidak stabil). Tabel 2 di atas menunjukkan struktur faktor yang terbentuk belum murni atau fit karena masih ada aitem yang crossloading dan ada 2 faktor yang tidak stabil karena hanya terdiri dari 2 aitem. Jika terjadi hal yang demikian, maka bisa dilakukan dengan menaikkan nilai loading dari 0.3 menjadi 0.4. setelah dilakukan analisis kembali didapatkan 7 faktor dan masih ada aitem yang memiliki nilai yang cross loading. Adapun hasil dari analisis ini dapat dilihat pada tabel 3.

Tabel 3. Nilai Loading 0,40

Rotated Component Matrix ${ }^{a}$

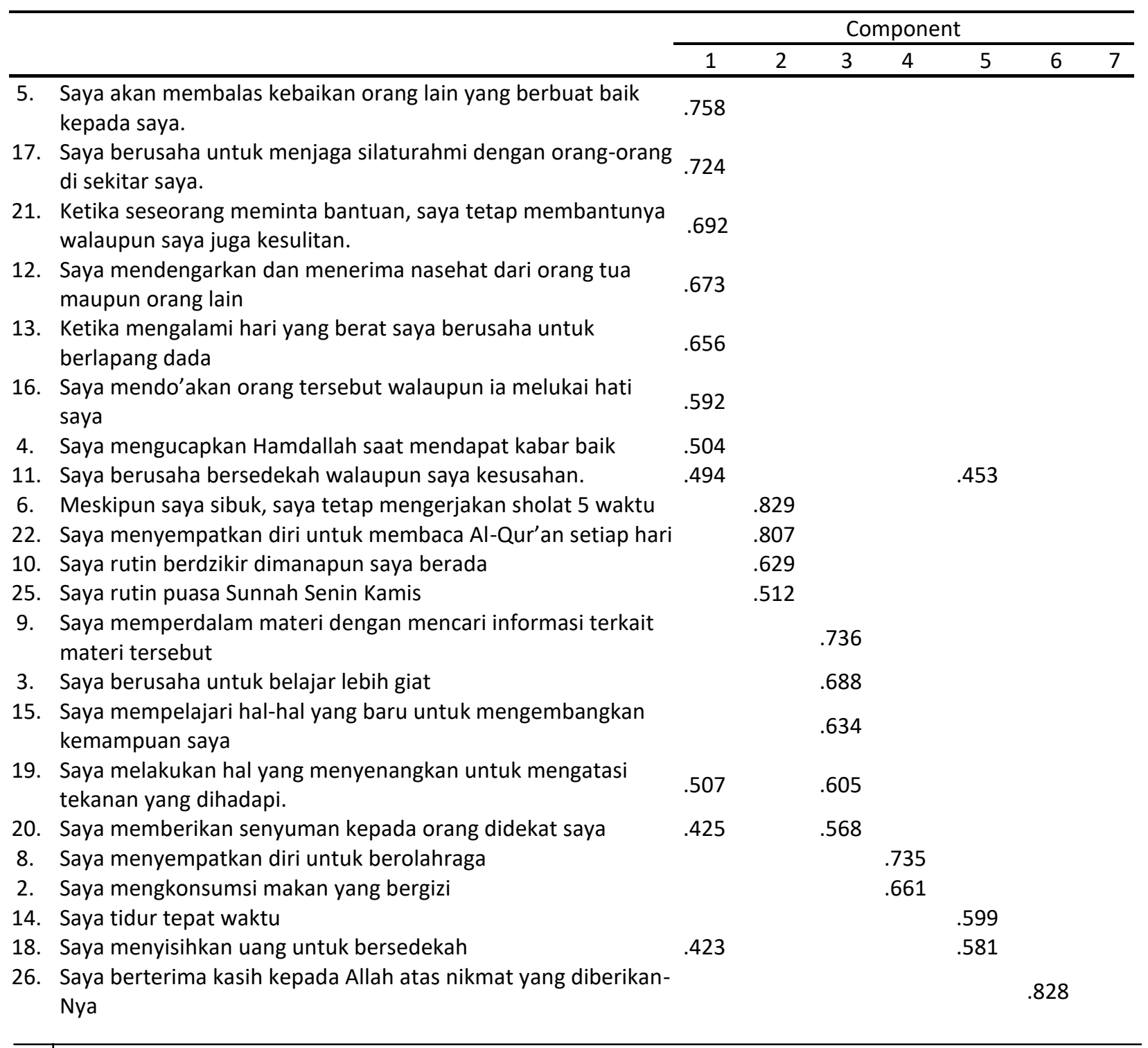


23. Saya berterima kasih kepada orang yang telah membantu saya.

24. Saya memberikan uang kepada orang yang meminta-minta, walaupun jumlah uang yang saya miliki sedikit.

7. Saya menerima dengan lapang dada ketika mendapat hal yang tidak sesuai dengan yang saya inginkan.

Extraction Method: Principal Component Analysis.

Rotation Method: Varimax with Kaiser Normalization.

a. Rotation converged in 14 iterations.

el 3 masih menunjukkan struktur faktor yang terbentuk belum murni atau fit karena masih ada aitem yang crossloading dan ada 1 faktor yang hanya terdiri dari 2 aitem. Oleh karena itu nilai loading dinaikkan kembali dari 0.4 menjadi 0.5. Adapun hasilnya dapat dilihat pada tabel 4 .

Tabel 4. Nilai Loading 0.50

Rotated Component Matrix ${ }^{a}$

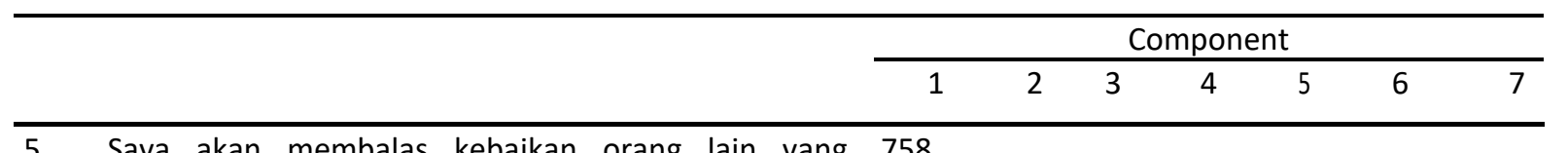

5. Saya akan membalas kebaikan orang lain yang .758 berbuat baik kepada saya.

17. Saya berusaha untuk menjaga silaturahmi dengan .724 orang-orang di sekitar saya.

21. Ketika seseorang meminta bantuan, saya tetap .692 membantunya walaupun saya juga kesulitan.

12. Saya mendengarkan dan menerima nasehat dari .673 orang tua maupun orang lain

13. Ketika mengalami hari yang berat saya berusaha .656 untuk berlapang dada

16. Saya mendo'akan orang tersebut walaupun ia .592 melukai hati saya

4. Saya mengucapkan Hamdallah saat mendapat kabar .504 baik

11. Saya berusaha bersedekah walaupun saya kesusahan.

6. Meskipun saya sibuk, saya tetap mengerjakan sholat 5 waktu

22. Saya menyempatkan diri untuk membaca Al-Qur'an setiap hari

10. 10. Saya rutin berdzikir dimanapun saya berada

25. Saya rutin puasa Sunnah Senin Kamis

9. Saya memperdalam materi dengan mencari informasi terkait materi tersebut

3. Saya berusaha untuk belajar lebih giat

15. Saya mempelajari hal-hal yang baru untuk mengembangkan kemampuan saya

19. Saya melakukan hal yang menyenangkan untuk mengatasi tekanan yang dihadapi.

20. Saya memberikan senyuman kepada orang didekat 
saya

8. Saya menyempatkan diri untuk berolahraga

2. Saya mengkonsumsi makan yang bergizi

14. Saya tidur tepat waktu

18. Saya menyisihkan uang untuk bersedekah

26. Saya berterima kasih kepada Allah atas nikmat yang diberikan-Nya

23. Saya berterima kasih kepada orang yang telah membantu saya.

24. Saya memberikan uang kepada orang yang memintaminta, walaupun jumlah uang yang saya miliki sedikit.

7. Saya menerima dengan lapang dada ketika mendapat hal yang tidak sesuai dengan yang saya inginkan.
.735

.661

.599

.581

.828

.636

.685

.407

Extraction Method: Principal Component Analysis.

Rotation Method: Varimax with Kaiser Normalization.

a. Rotation converged in 14 iterations.

Tabel 4 menunjukkan struktur faktor yang terbentuk masih belum murni atau fit walaupun sudah tidak ada aitem yang crossloading akan tetapi masih ada faktor yang hanya terdiri dari 2 aitem. Costello dan Osborne (2005) mengatakan bahwa struktur faktor telah murni atau fit jika faktor loading lebih besar dari 0,3, tidak ada crossloading (satu aitem memiliki faktor loading yang tinggi pada dua atau lebih faktor yang terbentuk), dan dalam satu faktor minimal ada 3 aitem (faktor yang kurang dari 3 aitem dianggap tidak stabil). Dari tabel 4 bisa kita lihat masih ada 4 faktor yang hanya terdiri atas 2 aitem dan 1 aitem sehingga faktor tersebut digugurkan. Hal ini dapat dilihat pada tabel 5. Dari Hasil analisis didapatkan bahwa faktor 1 menerangkan $35.804 \%$ dari varians, faktor 2 menerangkan $12.937 \%$ dan faktor 3 menerangkan $8.665 \%$. 


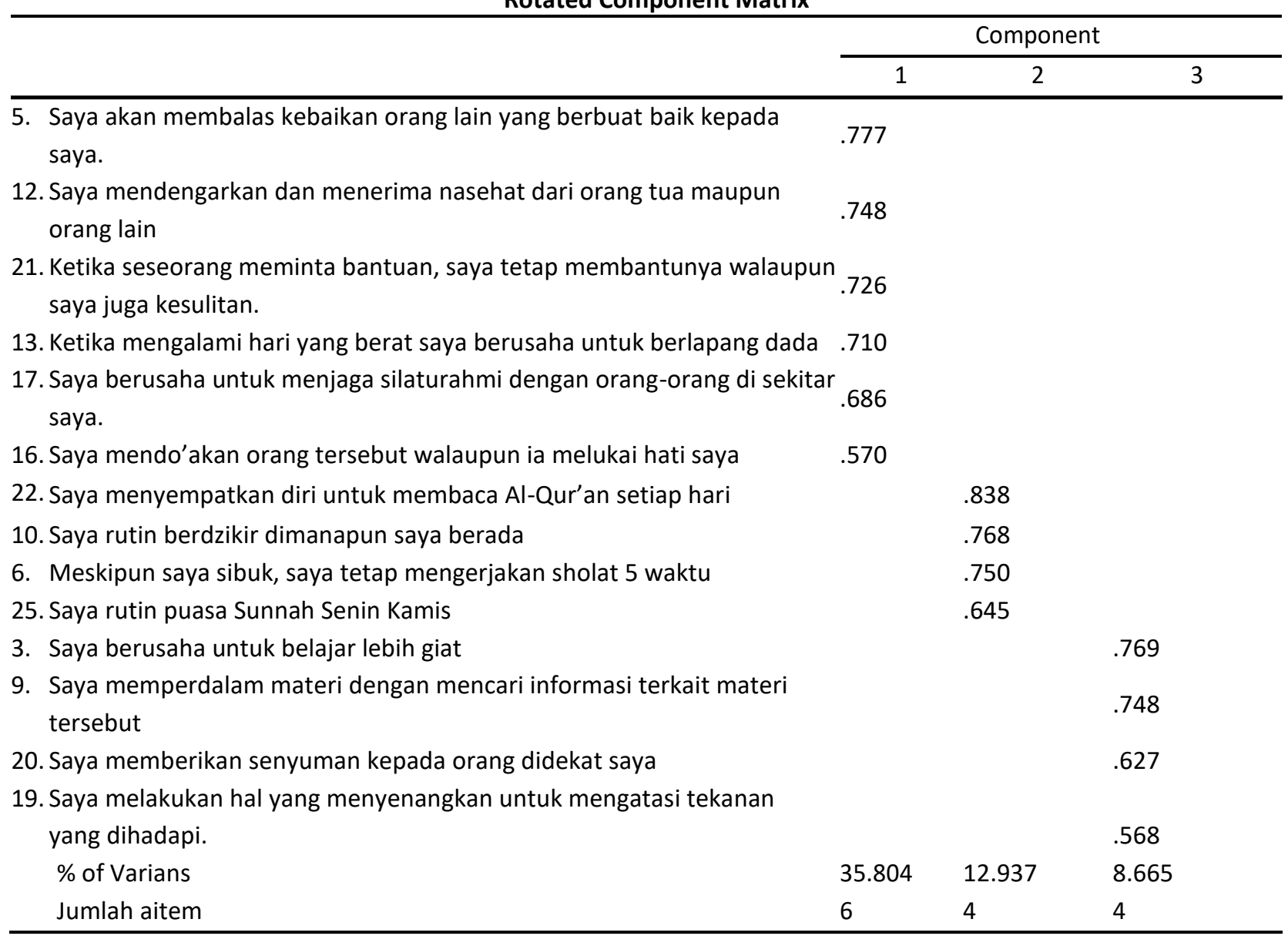

\subsection{Reliabilitas Alpha Cronbach}

Uji reliabilitas dalam penelitian ini menggunakan uji analisis cronbach alpha dengan bantuan spss 23. Pada penelitian ini dilakukan 2 kali uji reliabilitas yaitu uji reliabilitas tiap-tiap faktor dan uji reliabilitas secara keseluruahan. Pada uji reliabilitas faktor, pada faktor 1 hasil reliabilitasnya adalah 0.829 dan tidak aitem yang digugurkan. Corrected item total correlation bergerak dari 0.578 sampai 0.645 Pada faktor 2 , nilai relibilitas yang didapatkan adalah 0.780 .

Corrected item total correlation bergerak dari 0.488 sampai 0.677 . Pada faktor 3 , nilai reliabilitas yang didapatkan adalah 0.729 . Corrected item total correlation bergerak dari 0.475 sampai 0.542 . Uji reliabilitas kesuluran aitem diketahui nilai cronbach alpha yang didapatkan adalah 0.851 dengan nilai Corrected item total correlation bergerak dari 0.413 sampai 0.608 . Dari hasil uji reliabilitas dapat diketahui bahwa alat ukur kebersyukuran ini reliable (ajeg).

\subsection{Analisis Faktor}

Tahap ini merupakan tahap awalan sebelum dapat dilakukan analisis faktor. Dalam tahap ini, ada dua hal yang perlu dilakukan agar analisis faktor dapat dilaksanakan, yang pertama yaitu menentukan besaran nilai Barlett Test of Sphericity, yang digunakan untuk mengetahui apakah ada korelasi yang signifikan antar variabel, dan kedua adalah Keiser-Meyers-Oklin (KMO) Measure of Sampling 
Halimatussa'diah, Milya Zakiyah, Muthia Muslimah Almih, Satriani, Yang Dini Azkarisa, dan Dian Sari Utami

Adequacy, yang digunakan untuk mengukur kecukupan sampel dengan cara membandingkan besarnya koefisien korelasi yang diamati dengan koefisein korelasi parsialnya.

\section{Diskusi}

Hasil dari skala yang telah di sebarkan kepada 132 mahasiswa muslim di berbagai universitas dan jurusan di Yogyakarta menunjukkan bahwa skala kebersyukuran yang di buat bisa di gunakan untuk mengukur kebersyukuran itu sendiri khususnya pada mahasiswa muslim. Uji validitas dilakukan dengan menggunakan Validitas konstruk dengan menggunakan analisis faktor. Analisis faktor yang digunakan dalam penelitian ini adalah exploratory factor analisis. Hasil dari uji validitas tersebut menunjukkan bahwa faktor 1 dinamai dengan "menjaga hubungan baik kepada sesama" dengan nilai varians $35.804 \%$ dari faktor 2 yang dinamai dengan "menjaga ibadah" dengan nilai sebesar $12.937 \%$ dan faktor 3 yang dinamai dengan "menghargai diri" dengan nilai sebesar $8.665 \%$.

Hasil uji reliabilitas skala ini sebesar 0.851. Hal ini menunjukkan skala ini besaran nilai Barlett Test of Sphericity adalah 455.929 dengan taraf signifikansi 0,000 yang berarti ada korelasi yang signifikan di antara variabel. Hasil perhitungan KMO sebesar 0,830 menunjukkan bahwa kecukupan sampel termasuk kategori atas.

Analisis faktor yang digunakan yaitu analisis faktor eksploratori (EFA). Analisis faktor eksploratori adalah salah satu metode analisis faktor untuk mengidentifikasi hubungan antara variabel manifest atau variabel indikator dalam membangun sebuah konstruk. Tabel ini menunjukkan bahwa aitem ini dapat dianalisis karena koefisiensi korelasi anti-image berada diatas 0,5 dapat digunakan untuk asesmen maupun untuk mengambil data penelitian mengenai kebersyukuran. Meskipun demikian, alat ukur ini memiliki keterbatasan. Alat ukur hanya dapat digunakan pada subyek yang beragama Islam. Selain itu, alat ukur ini mungkin perlu dikembangkan lagi dengan subyek yang berbeda-beda karakteristik atau dalam kelompok usia yang berbeda.

\section{Daftar Pustaka}

Al-Banjari, R. R. (2014). Ajaibnya syukur atasi semua masalah. Yogyakarta: Sabil.

Al-Fauzan, A. S. (2013). Menjadi hamba yang pandai bersyukur. Solo: Aqwam.

Arif, I. S. (2016). Psikologi positif: pendekatan saintifik menuju kebahagiaan. Jakarta: Gramedia.

Costello, A. B., \& Osborne, J. W. (2005). Exploratory Factor Analysis: Four recommendations for getting the most from your analysis. Practical Assessment, Research, and Evaluation, 10(7), 1-9.

Emmons, R. A., McCullough, M. E., \& Tsang, J. A. (2002). The grateful disposition: a conceptual and empirical topography. Journal of Personality and Social Psychology, 82, 112-127.

Imam Al- Asy-Syifa.Ghazali (2005). Ihya' Ulumudiin, diterjemahkan oleh Mohammad Zuhri,dkk. Semarang: CV 
Onwuegbuzie, A. J., \& Leech, N. L. (2005). A typology of errors and myths perpetuated in educational research textbooks. Current Issues in Education, 8(7).

Peterson, C., \& Seligman, M. E. P. (2004). Character strenght and virtues: a handbook and classification. Washington DC: Oxford University Press.

Pruyser, P. W. (1976). The minister as diagnostician: Personal problems in pastoral perspective. Philadelphia: Westminster Press.

Rauf, R. S., \& Alif, U. (2008). Inilah rahasia bersyukur. Yogyakarta: DIVA Press.

Romdhon, A. (2011). kebersyukuran Sebagai Sebuah Strategi Coping. Jurnal dipresentasikan pada kongres Asosisasi Psikologi Islam Ke-3 di Malang

Seligman, M.E.P. (2005). Authentic Happiness: Menciptakan Kebahagiaan dengan Psikologi Positif. Bandung: PT. Mizan Pustaka

Sheldon, M. K. \& Sonja, L. (2006). "How To Increase And Sustain Positive Emotion: The Effects Of Expressing Gratitude And Visualizing Best Possible Selves", The Journal of Positif Psychology, hlm. 73-82 